\title{
Expression and characterization of novel ovine orthologs of bovine placental prolactin-related proteins Koichi Ushizawa ${ }^{1}$, Toru Takahashi*1, Misa Hosoe ${ }^{1}$, Katsuhiro Ohkoshi ${ }^{1}$ and Kazuyoshi Hashizume ${ }^{2}$
}

\author{
Address: ${ }^{1}$ Reproductive Biology Research Unit, Division of Animal Sciences, National Institute of Agrobiological Sciences, 2 Ikenodai, Tsukuba, \\ Ibaraki 305-8602, Japan and 2Department of Veterinary Medicine, Faculty of Agriculture, Iwate University, 3-18-8 Ueda, Morioka, Iwate 020-8550, \\ Japan \\ Email: Koichi Ushizawa - ushizawa@affrc.go.jp; Toru Takahashi* - tatoru@affrc.go.jp; Misa Hosoe - hosoe@affrc.go.jp; \\ Katsuhiro Ohkoshi - koshisan@affrc.go.jp; Kazuyoshi Hashizume - kazuha@iwate-u.ac.jp \\ * Corresponding author
}

Published: 25 October 2007

BMC Molecular Biology 2007, 8:95 doi:10.1 186/I47|-2199-8-95

This article is available from: http://www.biomedcentral.com/I47/-2/99/8/95

() 2007 Ushizawa et al; licensee BioMed Central Ltd.

This is an Open Access article distributed under the terms of the Creative Commons Attribution License (http://creativecommons.org/licenses/by/2.0), which permits unrestricted use, distribution, and reproduction in any medium, provided the original work is properly cited.
Received: 15 May 2007

Accepted: 25 October 2007

\begin{abstract}
Background: The prolactin-related proteins (PRPs) are non-classical placental-specific members of the prolactin/growth hormone family. Among ruminants, they are expressed in the cotyledonary villi of cattle and goat. We investigated placental PRP in sheep in order to gain a comprehensive understanding of the function and evolution of these molecules. We also examined the sequence properties, expression and lactogenic activation of the cloned genes.

Results: We cloned two novel ovine PRPs, named oPRPI and oPRP2. oPRP2 had a typical PRP sequence similar to bovine PRPI (bPRPI). oPRPI had a short sequence identical with bovine or caprine type PRP but the reading frame was shifted. Both oPRPs were expressed in trophoblast giant binucleate cells (BNC) as in cattle and goat. oPRPI expression declined from the early to the middle stage of gestation. In contrast, OPRP2 expression remained constant throughout the gestation period. oPRP2 was translated to form a mature protein in a mammalian cell expression system. Western blotting showed a molecular mass of $35 \mathrm{kDa}$ for the FLAG-tag fusion oPRP2 protein. This recombinant protein and bPRPI were bioassayed using Nb2 lymphoma cells; it was confirmed that neither ruminant $P R P$ had lactogenic activity because the $\mathrm{Nb} 2$ lymphoma cells did not proliferate.

Conclusion: We have identified two novel PRPs, oPRPI and oPRP2, in ovine placenta. Both these ovine PRPs were localized and quantitatively expressed in BNC. Absence of lactogenic activity was confirmed for the oPRP2 molecule. It is anticipated that novel and known ruminant PRPs have common functions, except for lactogenic activity.
\end{abstract}

\section{Background}

Prolactin-related proteins (PRPs) are non-classical members of the prolactin (PRL)/growth hormone (GH) family that have been found in bovine, caprine, murine and rat placenta. In cattle, placental lactogen (PL) and thirteen types of placental PRPs have so far been reported [1-3]. In goats, PL has been detected in the placenta [4], and two newly-discovered PRPs were reported as PRL-related molecules in our recent study [5]. In ruminants, specifically in cattle, sheep and goats, trophoblast-specific genes such as $P L[4,6,7]$, pregnancy-associated glycoproteins (PAGs) [811], interferon-tau (IFNT) [12-14], trophoblast kunitz 
domain proteins (TKDPs) $[15,16]$ and cathepsins (CTSs) $[17,18]$ are known to be key factors for implantation and placentation, and are expressed in trophoblast cells including trophoblast giant binucleate cells (BNC). However, no molecules similar in sequence to bovine and/or caprine PRPs have been reported in sheep. It is assumed that PRP orthologs are involved in ovine placenta because placental PRL-like molecules have been discovered in many mammals, not only in cattle and goat but also in mouse and rat $[1-3,19]$. In the present study, we identified the mRNAs of two novel PRPs in ovine placenta and investigated their expression in the ovine placentome. We named them ovine prolactin-related protein-1 (oPRP1) and prolactin-related protein-2 (oPRP2) on the basis of similarities with cattle and goat sequences. They were translated in a HEK293 cell transfection system, as in the case of cattle [20,21]. Their lactogenic activities were confirmed by an Nb2 lymphoma cell bioassay [22-24]. An aim of future research will be to determine the function of ruminant PRP molecules that appear in the placenta. A crucial part of such a study will be to express ruminant PRP in other species. The purposes of the present study are (i) to explore a bPRP homolog gene in ovine placenta, (ii) to investigate the localized and quantitative expression of oPRP and (iii) to examine the possible biological activity of oPRP, because comparison among ruminant PRP structures and/or expression may provide clues to understanding PRP function.

\section{Results \\ oPRPI and oPRP2 nucleotide sequences and deduced amino acid sequences}

Full-length $O P R P 1$ and $O P R P 2$ were cloned from the ovine placentome on day 95 of gestation. oPRP1 was 893 nucleotides (nts) long with a 540-nts protein coding sequence region (CDS); $o P R P 2$ had a 947-nts full-length sequence and a 717-nts CDS. The protein sequences deduced from the full-length cDNAs comprised 179 amino acids (aa) in oPRP1 and 238 aa in oPRP2. The sequence region in which $O P R P 1 \mathrm{mRNA}$ is defective compared to other PRP mRNAs is shown in Fig. 1 along with the sequences of oPRP2, $C P R P 1$ and $b P R P 1$. oPRP1 has a shorter sequence, lacking $52 \mathrm{bp}$ from the CDS regions of other PRP sequences (positions 529-580). Since the reading frame of the codon is shifted at the 52 bp defect, the CDS region became $540 \mathrm{bp}$.

Fig. 2 shows a phylogenetic tree analysis based on the predicted aa sequences of the new oPRPs and other prolactin family members in cattle and goat. We confirmed a close phylogenetic relationship between oPRP1 and bPRP1, bPRP2, bPRP4, bPRP9, bPRP12, bPRP14 and cPRP1, which have known sequences. OPRP2 was considerably more distant from bPRP1, bPRP2, bPRP4, bPRP9,

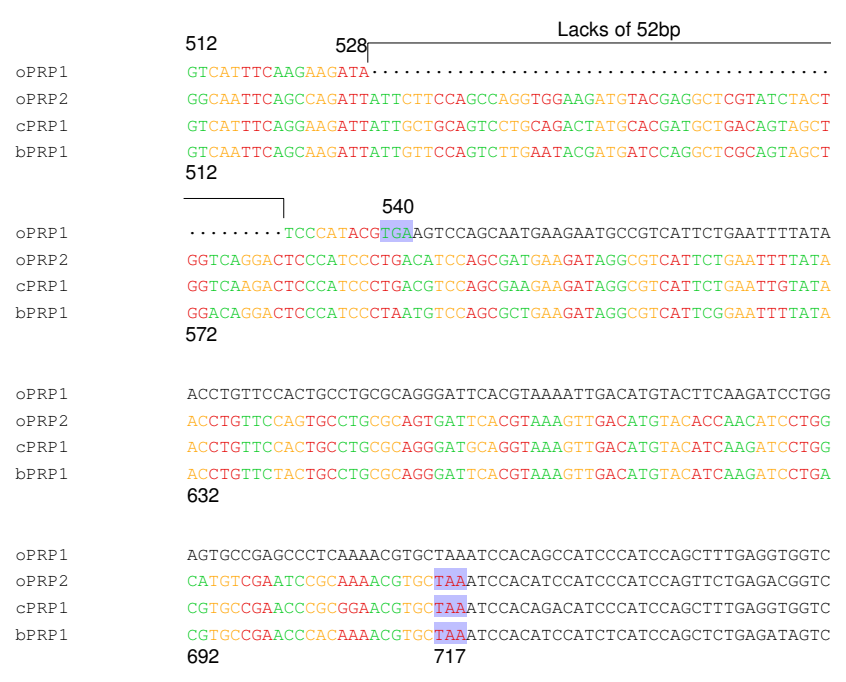

\section{Figure I}

The stop codon region of PRPs mRNA. oPRP2, bPRPI and $C P R P I$ have a stop codon 717 bp from the CDS start site. In oPRPI the stop codon is shifted to 540 bp from the CDS start. The shaded boxes indicate the stop codon. The sequence gaps are shown by dots.

bPRP12, bPRP14 and CPRP1 in the phylogenetic tree analysis.

The identity of oPRP1 and oPRP2 with the phylogenetically neighbouring PRPs is demonstrated in Fig. 3 and Table 1 . The $N$-terminal regions of the oPRP1 and oPRP2 proteins are rich in hydrophobic amino acid residues, which is characteristic of signal peptides. The signal peptide sequence, which is composed of 36 amino acids, is well conserved in the bPRP and/or CPRP family [1,5]. The mature oPRP1 protein is predicted to have one disulfide bond with three cysteines (Cys). In contrast, the mature oPRP2 protein is predicted to have three disulfide bonds with six Cys. Normally, Cys is common to the 39, 42, 97, 215, 232 and 238 positions in bPRP1, bPRP2, bPRP4, bPRP9, bPRP12, bPRP14 and cPRP1 (Fig. 3). In contrast, oPRP1 lacked the Cys at positions 215, 232 and 238, because there is no sequence corresponding to positions 180-238 (Fig. 3). oPRP1 has one potential consensus sequence for typical $N$-glycosylation, an Asn-X-Ser/Thr (NXS or NXT) at positions 70-72 (Fig. 3). oPRP2 has two consensus sequences for $N$-glycosylation at positions $92-$ 94 and 146-148 (Fig. 3). Another atypical N-glycosylation site, Asn-X-Cys (NXC), was exhibited at positions 9597 in oPRP1 (Fig. 3). The two positions in oPRP2 coincided with those in bPRP2, bPRP4, bPRP9 and bPRP14 (Fig. 3) $[1,20,21]$. In contrast, the typical position (7072 ) in oPRP1 coincided with those in bPRP1 and CPRP1, 


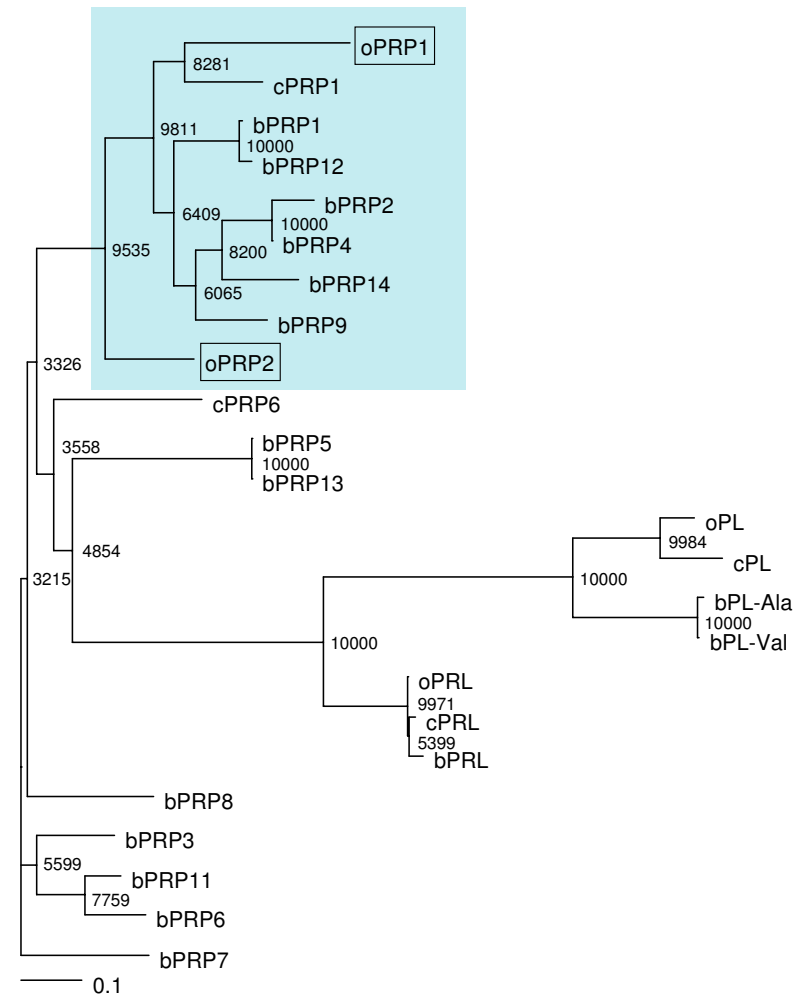

Figure 2

Phylogenetic tree of prolactin and placental-prolactin family of sheep, cattle and goat. The tree was constructed using TreeView following the alignment of protein sequences given by the Clustal W I.83 algorithm. The numbers at the base of each branch division represent bootstrap values after 10,000 repeats. The scale bar represents 0.1 amino acid replacements per amino acid site. For GenBank/ DDBJ accession numbers, refer to Materials and Methods. The proteins in light blue areas were used for the multiple alignments in Fig. 3.

while the atypical position (95-97) coincided with those in CPRP1 and bPRP9 $[1,5,20,21]$.

The predicted 3D structures of mature oPRP1 and oPRP2 are illustrated in Fig. 4. In general, PRL family members are predicted to have four $\alpha$-helices, like oPRP2, but oPRP1 may have only three $\alpha$-helices (Fig. 4). The oPRP1 sequence has a premature stop codon because the reading frame is shifted; residues $529-580$ (52 bp) in the other PRP sequences are absent (Fig. 1). The deduced molecular

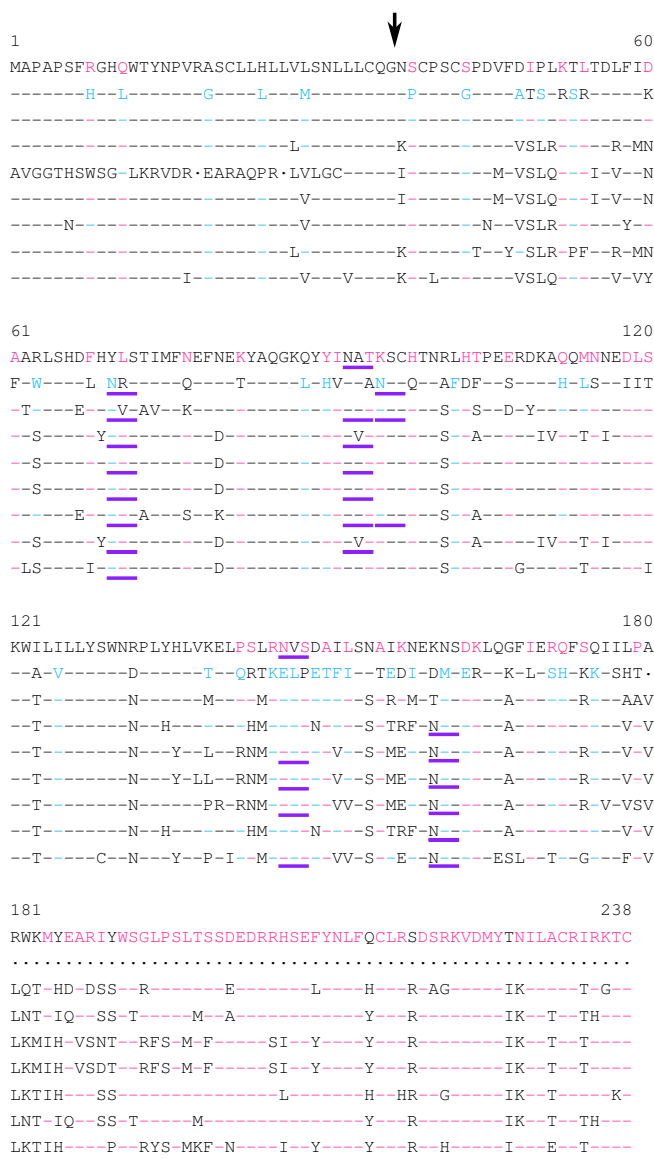

Figure 3

Comparison of amino acid sequences of oPRPI and oPRP2 with phylogenetically neighbouring PRPs. Residues identical to oPRPI and oPRP2 are shown by black hyphens, residues present only in oPRP2 by pink hyphens, and residues present only in oPRPI by blue hyphens. The sequence gaps are shown by dots. The amino acid sequences were aligned with the help of Clustal W I.83 on the DDBJ web site. The arrow indicates the putative primary cleavage site of the signal peptide of oPRPI or oPRP2. The potential $\mathrm{N}$-glycosylation site is underlined in purple.

structure predicts that this protein lacks the fourth $\alpha$-helix found in existing bovine or caprine PRPs (Fig. 4). Structural differences in the $N$-glycosylation site, the disulfide bond (-S-S-) between Cys97 and Cys215 and each atomic configuration were also exhibited (Fig. 4).

Table I: Identity of oPRPI and oPRP2 for phylogenetically neighbouring PRPs (\%)

\begin{tabular}{lccccccc}
\hline & bPRPI & bPRP2 & bPRP4 & bPRP9 & bPRPI2 & bPRPI4 & cPRPI \\
\hline oPRPI & 64 & 53 & 66 & 67 & 63 & 63 & 73 \\
oPRP2 & 71 & 60 & 71 & 71 & 71 & 68 & 71 \\
\hline
\end{tabular}



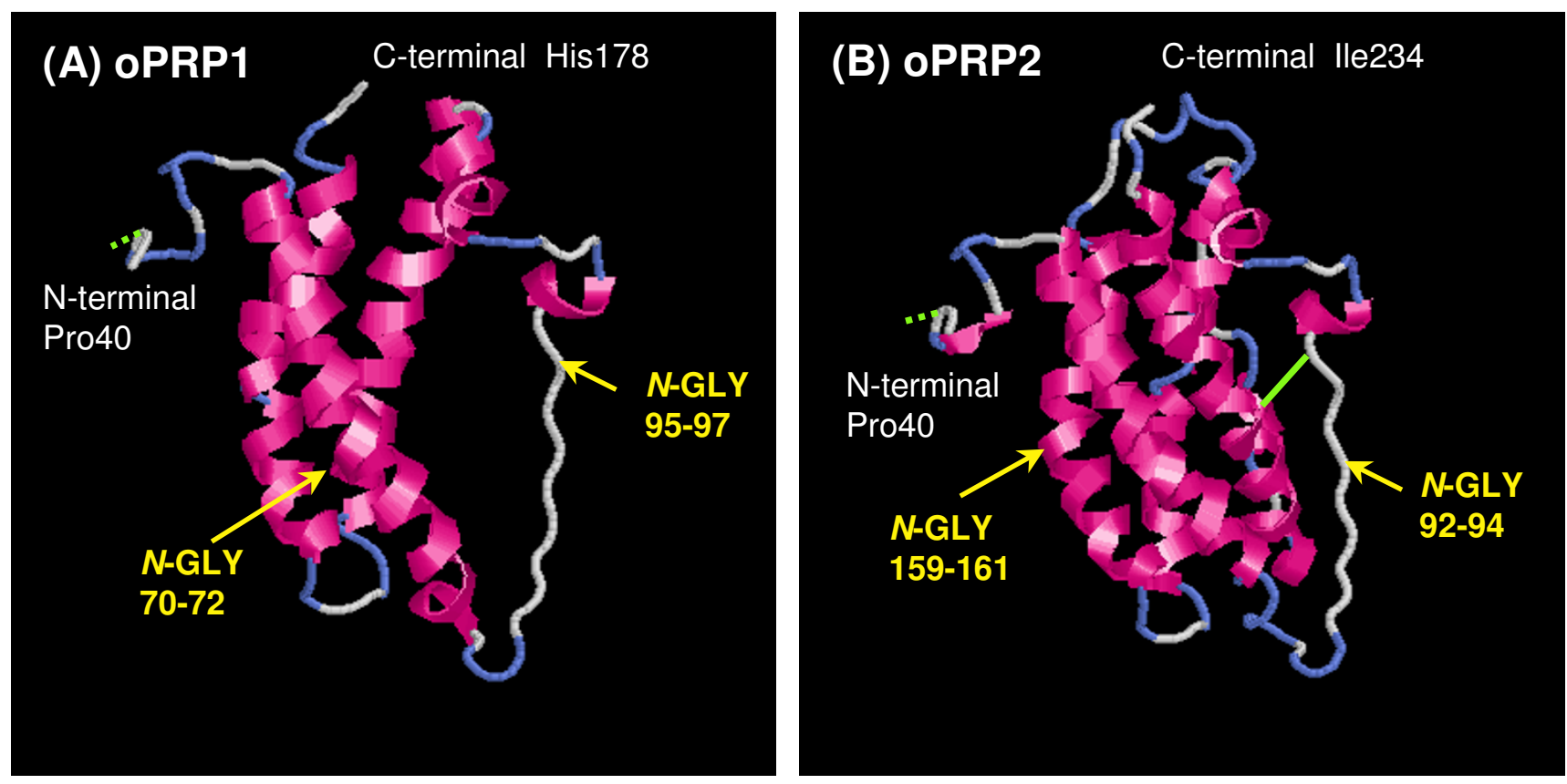

Figure 4

The predicted 3D structures of mature (A) oPRPI and (B) oPRP2 proteins. The 3D structures were predicted by FAMS software. The oPRPI structure was constructed in the Pro40-His I 78 region. The oPRP2 structure was constructed in the Pro40-lle234 region. Disulfide bonds are shown as light green solid lines, predicted disulfide bonds as light green dotted lines. N-GLY indicates the potential $N$-glycosylation site.

The oPRP1 and oPRP2 sequences were submitted to the DNA Data Bank of Japan (DDBJ); the DDBJ/GenBank accession numbers are $\underline{\mathrm{AB} 231297}$ and $\underline{\mathrm{AB} 231298}$.

\section{Localization and quantitative expression of oPRP I and oPRP2 mRNA}

Specific expression of $o P R P 1$ and $o P R P 2$ mRNA was detected in ovine placenta (Fig. 5) by conventional RTPCR. No signal was observed in other ovine tissues, i.e. heart, liver, lung, kidney, spleen and endometrium.

oPRP1 and oPRP2 mRNAs were localized by in situ hybridization in the ovine placentome (Fig. 6). DIG-labeled oPRP1 and oPRP2 anti-sense RNA probes specifically detected the mRNA transcript in the placentomes. Both oPRP1 and $O P R P 2$ appeared in the BNC in the cotyledonary villi area (Fig. 6). No significant $o P R P 1$ or $o P R P 2$ signals were detected using sense probes (Fig. 6).

Quantitative expression of $O P R P 1$ and $o P R P 2$ is shown in Fig. 7. In the placentomal tissue (the cotyledonary and caruncular parts: PTM), the intensity of oPRP1 expression declined from Day 45 to Day 95 and then remained constant to Day 135. The intensity of oPRP2 expression remained constant between the early (Day 45) and late (Day 135) stages of gestation. In the intercotyledon (the membrane between the cotyledonary villi: ICOT), oPRP1 expression declined from the early (Day 45) to the late (Day 135) stages of gestation. Again, as in the placentome, oPRP2 expression remained constant between the early

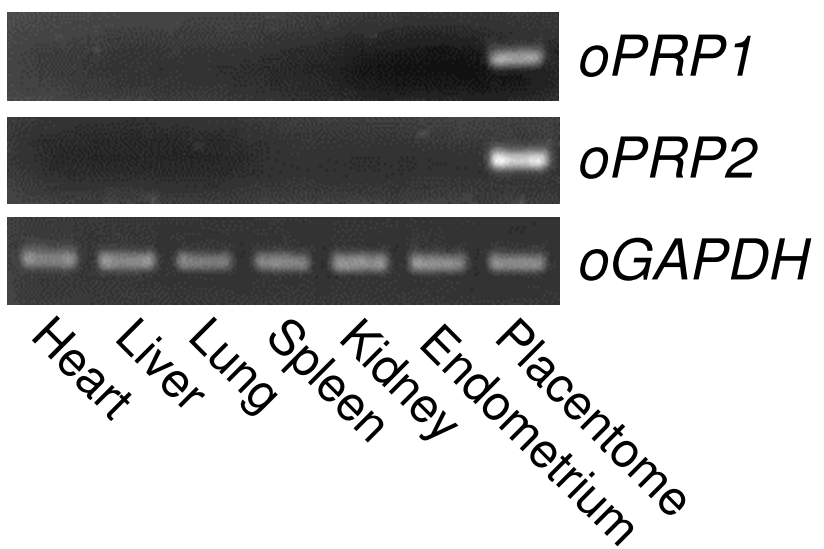

Figure 5

Expression of oPRPI and oPRP2 mRNA in ovine tissues. Heart, liver, lung, spleen, kidney and endometrium were used for RT-PCR. Cotyledonary tissue at Day 45 of gestation was used as a placental sample. GAPDH expression in each tissue is presented as a control. 

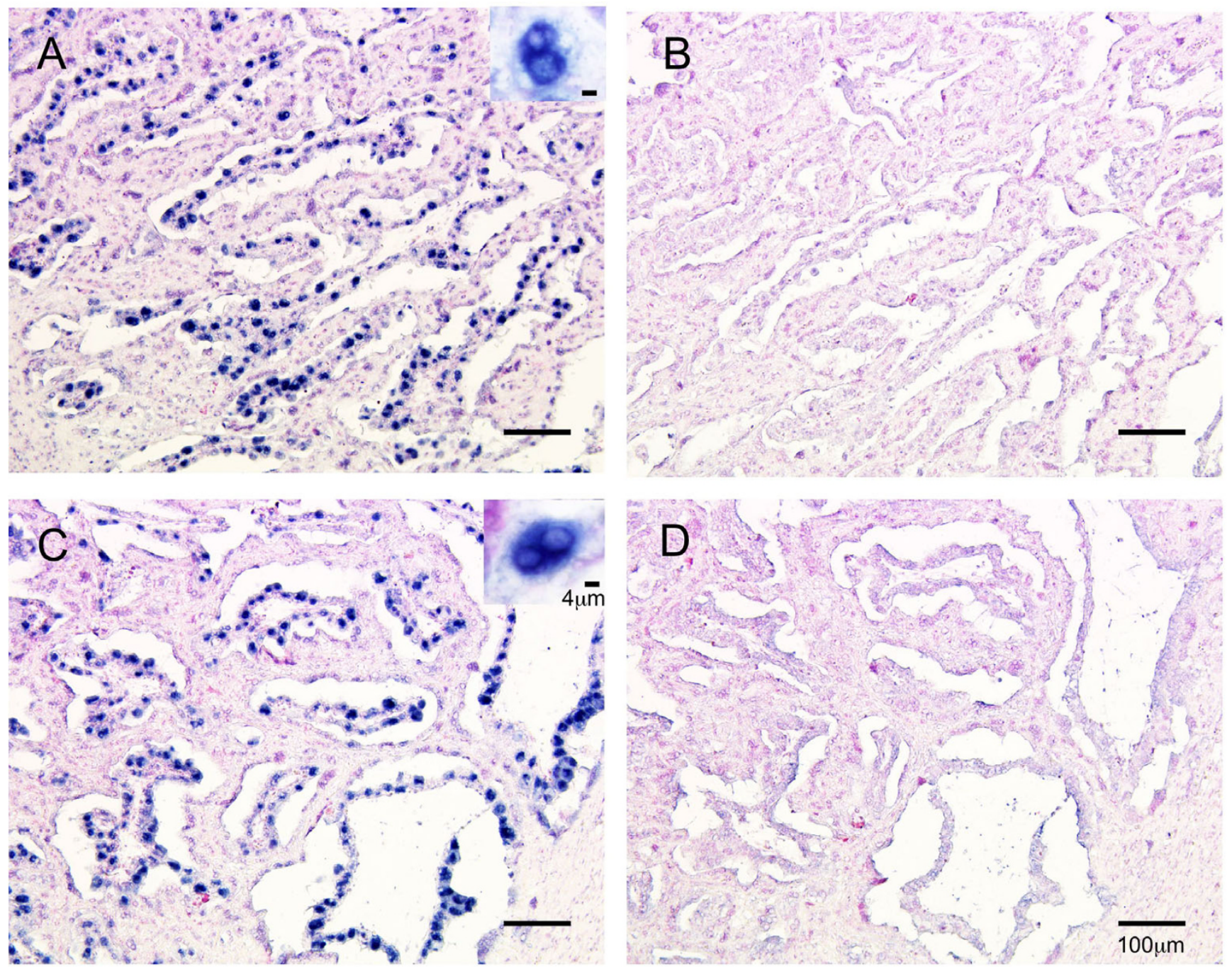

\section{Figure 6}

Localization of oPRPI and oPRP2 in ovine placentome on Day 45 of gestation. (A, B) oPRPI and (C, D) oPRP2 mRNAs were detected by in situ hybridization. (A, C) DIG-labeled anti-sense CRNA probes were used. (B, D) DIG-labeled sense cRNA probes were used. Seven micrometer sections of ovine placentome were hybridized with each probe. Scale bars $=100 \mu \mathrm{m}$ (main areas in A, B, C and D) and $4 \mu \mathrm{m}$ (right upper areas in A and C).

(Day 45) and late (Day 135) stages. There was more intense oPRP1 expression in ICOT than in PTM during the early (Day 45) to middle (Day 95) stages of gestation. In contrast, oPRP2 expression was greater in the PTM than ICOT throughout pregnancy.

\section{Production of recombinant proteins}

We produced oPRP2 recombinant protein in order to investigate its lactogenic activity. Cloned oPRP2 sequences were efficiently translated in an HEK293 cell system, as in the case of bovine PRPs (Fig. 8) [20,21]. A FLAG-tag fusion oPRP2 protein was translated at approximately 35 kDa (Fig. 8). We also tried to produce recombinant oPRP1 protein in a mammalian cell system but were unable to do so.

\section{Lactogenic activity of PRP}

Ovine PRL (positive control) stimulated Nb2 lymphoma cell proliferation effectively, and another lactogenic protein, bovine PL, showed stimulatory activity (Fig 9). No stimulatory activity was detected in recombinant OPRP2, as for bPRP1.

\section{Discussion}

The diversity of the PRL gene family has been demonstrated in mouse, rat, cattle and goat, but functional infor- 

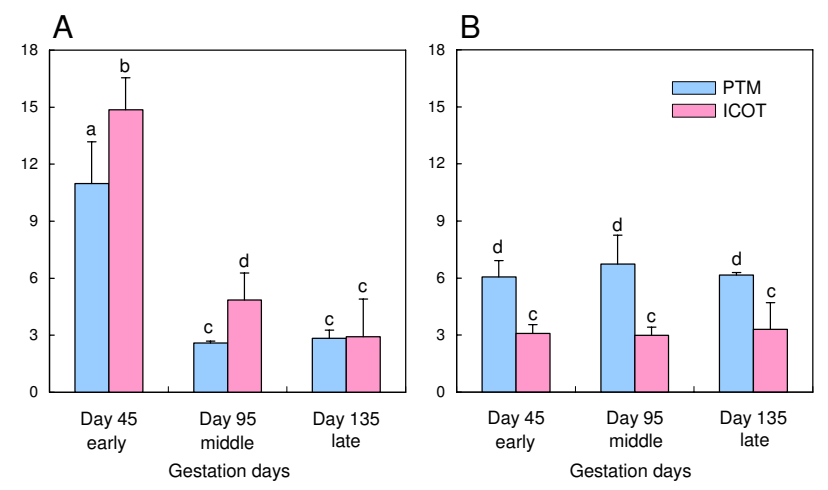

Figure 7

QPCR analysis of (A) oPRPI and (B) oPRP2 mRNA in ovine placenta. Total sheep RNA was extracted from PTM and ICOT on Day 45 (early), Day 95 (middle) and Day 135 (late) of gestation. Expression of these mRNAs was normalized to the expression of GAPDH measured in the corresponding RNA preparation. Values are means \pm SEM. Values with different letters ( $a, b, c$ and $d)$ are significantly different $(P<0.05)$.

mation about these proteins is limited except for PRL, PL and some rodent prolactin-like proteins (Prlps) [2,19,2529]. In particular, ruminants commonly have various genes of this family, but there is no information regarding sheep, even though anatomical evidence shows that placentae are similar among bovidae $[1,20,21,30,31]$. Thirteen varieties of PRP paralogs have been reported in bovines and two in goat $[1,5,20,21]$. In the present study, we have identified novel PRPs in sheep and compared the properties of sheep and cattle/goat.

The novel oPRP1 and oPRP2 genes were detected in and cloned from ovine placenta and oPRP1 was deduced to have a shortened amino acid sequence. Phylogenetic analysis suggests that PRP molecules evolved as ruminant species diverged, because these ovine PRPs are phylogenetically adjacent to caprine and bovine PRPs (Fig. 2).

We confirmed the short variant form of PRP in ovine placenta (Figs. 3 and 4). Although there is no report that short variant forms result from alternative splicing or proteolytic cleavage in non-classical members of the PRL family, namely bovine PRP, caprine PRP, mouse Prlp and rat Prlp $[1,2,5,25,26]$, short variants of bPL and PRL have been reported $[32,33]$. Two types of short $b P L$ variant are formed by alternative splicing [34]. One has a premature stop codon because of a shift in the reading frame. Although the defective position in the $b P L$ variant sequence was similar to that in $O P R P 1, b P L$ lacked only 23 bp in this region. It is not yet known whether the short bPL variant exists or what function it may have. Some

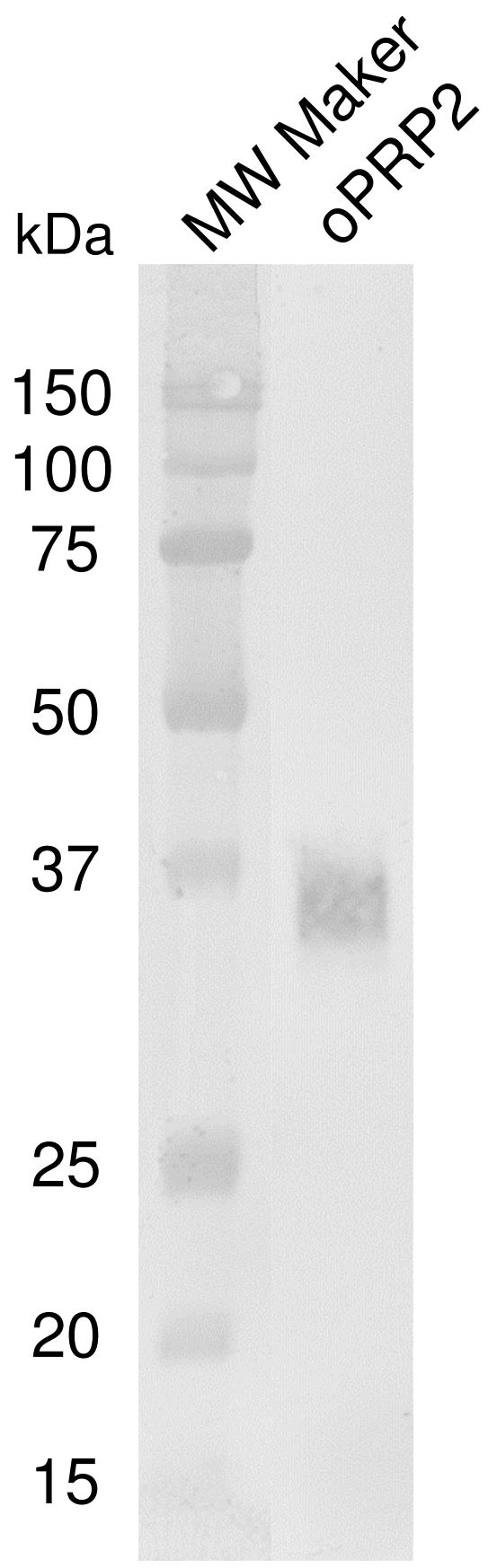

\section{Figure 8}

Western blot analysis of recombinant FLAG-tag fusion oPRP2 protein. Conditioned media from HEK 293 cells transiently transfected with each gene were collected, and the purified proteins ( $\mathrm{Ing}$ ) were loaded on to separate lanes. The proteins were separated by SDS-PAGE and specific proteins were detected by Western blot analysis using an anti-FLAG antibody. MW Marker: molecular weight marker. 


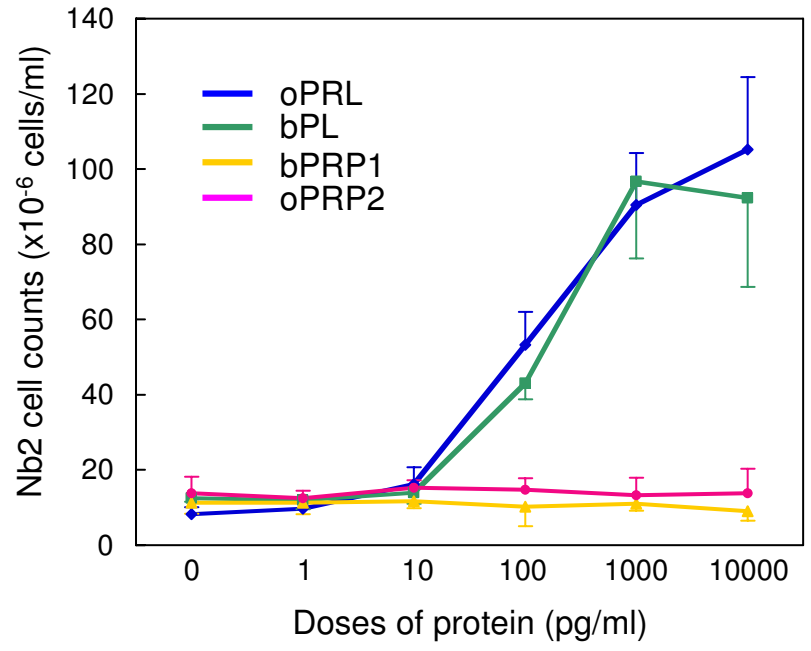

\section{Figure 9}

Lactogenic activity of oPRP2 and bPRPI. Nb2 lymphoma cell proliferation and PRP dosage are shown. oPRL and bPL were used as positive controls. Values are means \pm SD.

structural variants of PRL proteins have been confirmed in various mammalian species [32]. A short fragment of PRL protein has also been confirmed in rat, mouse and human [35-37]. Although these short PRL (16 kDa-PRL) molecules may result from alternative splicing, they could also be generated by proteolytic cleavage. The cleavage site (positions 145-149 in the mature region) almost coincides with the position of the oPRP1 stop codon. These short PRLs in mouse and human are known to have potential as inhibitors of capillary endothelial cell proliferation [38,39]. The short PRL in rat produces an anti-angiogenic effect via an unique, high-affinity, saturable receptor that is different from the PRL receptor [40]. Whether oPRP1 corresponds to the short PRL receptor is not certain, because full-length PRL binds to the PRL receptor and some ruminant PRPs do not. However, one hypothesis may be that oPRP1 has an inhibitory effect on the proliferation of vascular endothelial cells, because the sequence length and the mature protein region are similar to those of the short PRL variants in human and rodents. Members of the rodent Prl superfamily, namely prolactinlike proteins (Prlp), proliferins (Plf) and proliferin-related protein (Plfr), are non-classical and have several specific activities such as angiogenesis [41-43], hematopoiesis [44-46] and immunomodulation [47-50]. A possible hypothetical function for OPRP1 may be in the regulation of angiogenesis, but its actual function remains to be clarified.

Primary expression of $o P R P 1$ and $o P R P 2$ mRNA was observed in BNC (Fig. 6). The localization of $o P R P$
mRNAs is similar to that of PRP family members in other ruminants $[5,20,21,30,31,51]$. The mRNAs of both oPRPs were detected in the PTM and ICOT tissues throughout pregnancy (Fig. 7). However, the expression patterns were different; oPRP1 expression declined with the progress of the pregnancy in PTM and ICOT, but in contrast, oPRP2 expression remained constant throughout pregnancy. However, there seems to be a discrepancy between the localization and quantitative expression of oPRP2: quantitative real-time RT-PCR (QPCR) data suggest that oPRP2 may be expressed not only in $\mathrm{BNC}$ but also in conventional trophoblast cells, as in bovine [20,21]. In $b P R P$ expression profiles, four types of expression pattern were found during pregnancy in PTM: (i) genes expressed around the window; (ii) genes with peak expression around mid-gestation; (iii) genes that show increasing expression during the progression of gestation and peak late in gestation; (iv) genes with approximately constant expression throughout gestation [34]. In the present study, although expression was not determined during the implantation period, oPRP1 expression may correspond to the type (ii) pattern. In contrast, oPRP2 expression might be type (iv) but without lactogenic activity. The functional significance of short PRPs and various other kinds of PRP in ruminant placenta is still unclear. We could produce recombinant oPRP2 protein as well as proteins of other ruminant species (cattle and goat) $[5,20,21]$. Only the absence of lactogenic activity is clearly confirmed for recombinant oPRP2 and bPRP1 by a bioassay using Nb2 lymphoma cells.

\section{Conclusion}

We have cloned two novel prolactin-related protein genes in ovine placentome. The ovine PRP sequences have a high homology with bovine PRP. However, oPRP1 has a premature stop codon, which has not been discovered in bovine and caprine PRPs. oPRPs were expressed in trophoblast BNC, as are bovine or caprine PRPs. Their mRNAs were expressed throughout gestation. oPRP1 mRNA declined with the progress of gestation; oPRP2 mRNA remained constant throughout. oPRP2 produced mature recombinant protein in a mammalian cell-expression system. We confirmed that oPRP2 is lactogenically inactive, as oPRP2 treatment did not induce proliferation of $\mathrm{Nb} 2$ lymphoma cells.

\section{Methods}

\section{Animals and tissues collection}

Ovine placental tissues for cDNA cloning, mRNA expression and in situ hybridization were collected from Corriedale sheep. The PTM and ICOT were collected at a local slaughterhouse on Days 45 ( $\mathrm{n}=3$ animals), 95 ( $\mathrm{n}=3$ animals) and 135 ( $\mathrm{n}=2$ animals) of gestation after natural mating (day 1). The collected samples were stored at $80^{\circ} \mathrm{C}$ prior to RNA extraction. The placentomes were fixed 
in 3.7\% formaldehyde PBS at pH 7.4 and then embedded in paraffin wax and stored at $4^{\circ} \mathrm{C}$ prior to in situ hybridization.

All procedures for these animal experiments were carried out in accordance with the guidelines and ethics approved by the Animal Ethics Committee of the National Institute of Agrobiological Sciences for the use of animals.

\section{Cloning of full-length oPRP cDNAs}

Full-length cDNAs of the novel oPRP1 and oPRP2 were isolated from ovine cotyledonary tissue by the 3'-rapid amplification of cDNA ends (RACE) method. In brief, complete RNA was isolated from an ovine placentome on day 45 of gestation using ISOGEN (Nippon Gene, Toyama, Japan). We performed 3'-RACE using a 3'-full RACE core set (Takara, Kyoto, Japan) with an oPRP-specific forward primer (5'-CTATGGTCAACAGGCGTCCTCA-3'). The oPRP primers were designed from bovine PRP sequences. The 3'-RACE products were sequenced using an ABI Prism 370 automatic sequencer (Applied Biosystems, Foster City, CA, USA) after cloning into a pGEM-T Easy vector (Promega, Madison, WI, USA).

\section{Phylogenetic analysis}

The deduced oPRP1 and oPRP2 protein sequences were aligned with the ruminant PRPs using the multiple alignment software Clustal W 1.83 on the DDBJ web site. Clustal W was also employed to calculate trees using the Neighbor-Joining (NJ) method [52]. TreeView was used to display the phylogenetic tree [53]. The values represent bootstrap scores for 10,000 trials, indicating the credibility of each branch. Except for the oPRP1 and oPRP2 sequences, the ruminant PRL family protein sequences were obtained from GenBank. Their GenBank accession numbers are: bPRP1 (L02944), bPRP2 (ㅆ27239), bPRP3

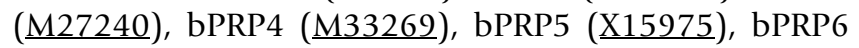

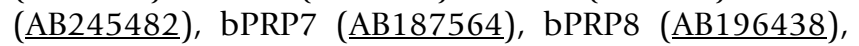
bPRP9 (吕204881), bPRP11 (BK005438), bPRP12 (BK005439), bPRP13 (BK005440), bPRP14 (吕255602),

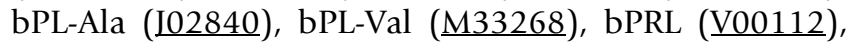
oPL (M31660), oPRL (M27057), caprine PRL (cPRL:

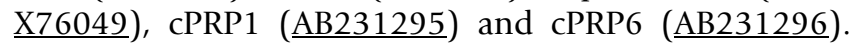
The cPL sequence was obtained from Sakal et al. [4].

\section{Three-dimensional structure prediction}

We predicted the three-dimensional (3D) structures of oPRP1 and oPRP2 using FAMS (Fully Automated Homology Modeling System) [54,55]. FAMS is a software program that predicts $3 \mathrm{D}$ models for target proteins on the basis of the structures of proteins that are known to be highly homologous. For oPRP1 and oPRP2, the 3D structure was constructed on the basis of that of human prolactin (hPRL) (Protein Data Bank ID: 1N9D). The FAMS program requires only an amino acid sequence as input and constructs 3D model structures automatically. The 3D structures were visualized using RasMol 2.7.3 software $[56,57]$.

\section{RT-PCR}

The tissue distribution of $O P R P 1$ and $O P R P 2$ expression was studied by RT-PCR. Ovine GAPDH was used as a positive control. Details of the RT-PCR method were described previously $[20,21]$. The total RNA in a reaction mixture was used for reverse transcription and template cDNA synthesis using oligo(dT) primers and Superscript III reverse transcriptase (Invitrogen, Carlsbad, CA, USA) at $50^{\circ} \mathrm{C}$ for $50 \mathrm{~min}$. Each PCR contained the cDNA template, primers, deoxynucleotide triphosphate mixture $(\mathrm{dNTP}), \mathrm{MgCl}_{2}, 10 \times$ PCR buffer II, autoclaved milliQ water and AmpliTaq gold DNA polymerase (Applied Biosystems). Amplification conditions included denaturation at $95^{\circ} \mathrm{C}$ for $30 \mathrm{~s}$ and extension at $72^{\circ} \mathrm{C}$ for $1 \mathrm{~min}$. Twenty-seven cycles were performed for all samples. The annealing temperature was set at $58^{\circ} \mathrm{C}$ for $30 \mathrm{~s}$. A single denaturation step at $95^{\circ} \mathrm{C}$ for $10 \mathrm{~min}$ before the first PCR cycle and a final extension step at $72^{\circ} \mathrm{C}$ for $10 \mathrm{~min}$ after the last PCR cycle were also performed. The PCR products were analyzed by agarose gel electrophoresis and visualized by ethidium bromide staining. The primers encoding the $o P R P 1$ and $o P R P 2$ sequences were designed using our obtained sequence. The designated primers are listed in Table 2. The primers were commercially synthesized (Tsukuba Oligo Service, Tsukuba, Japan).

\section{In situ hybridization}

The full-length $o P R P 1$ and $o P R P 2$ cDNAs were used as templates for hybridization probe synthesis. Digoxigenin (DIG)-labeled antisense and sense-complementary RNA

Table 2: Oligonucleotide primers used for RT-PCR analysis

\begin{tabular}{clcc}
\hline Gene & Primer & Sequence & Position \\
\hline oPRPI & Forward & 5' AACCCATGCCCGTCCTGCGGT 3' & $157-177$ \\
$($ AB231297 $)$ & Reverse & 5' TTAGCACGTTTTGAGGGCTCG 3' & $714-694$ \\
oPRP2 & Forward & 5' AACTCATGCCCATCCTGCAGT 3' & $155-175$ \\
$($ AB231298 $)$ & Reverse & 5' TTAGCACGTTTTGCGGATTCG 3' & $763-743$ \\
oGAPDH & Forward & 5' AAGGCCATCACCATCTTCCA 3' & $78-97$ \\
$($ AF030943 $)$ & Reverse & 5' AGGTCAGATCCACAACGGACA 3' & $603-583$
\end{tabular}


probes were prepared as described in previous studies $[20,21]$. The placentomes were sectioned into $7 \mu \mathrm{m}$-thick sections. In situ hybridization was performed using automated Ventana HX System Discovery with a RiboMapKit and BlueMapKit (Ventana, Tucson, AZ, USA) [20,21]. Briefly, ovine placentomal sections were hybridized with DIG-labeled probes in RiboHybe (Ventana) hybridization solution at $67^{\circ} \mathrm{C}$ for 6 hours. The sections were washed three times in RiboWash (Ventana) $\left(67^{\circ} \mathrm{C}, 6 \mathrm{~min}\right)$ after hybridization and fixed in RiboFix (Ventana) (both $37^{\circ} \mathrm{C}$, $10 \mathrm{~min}$ ). The hybridization signals were then detected using a monoclonal-anti-digoxin biotin conjugate (Sigma, Saint Louis, MI, USA). The hybridized slides were observed after preparation with a Leica DMRE HC microscope (Leica Microsystems, Wetzlar, Germany) with a Fujix digital camera HC2500 (Fujifilm, Tokyo, Japan).

\section{Quantitative real-time RT-PCR (QPCR)}

Expression of $O P R P 1$ and $O P R P 2$ was confirmed quantitatively at each stage of gestation by QPCR using the Power SYBR Green PCR master mix (Applied Biosystems). Fifty ng of total RNA was reverse-transcribed into cDNA for 30 min at $48^{\circ} \mathrm{C}$ using MultiScribe ${ }^{\mathrm{TM}}$ reverse transcriptase with a random primer, dNTP mixture, $\mathrm{MgCl}_{2}$ and RNase inhibitor. After heat inactivation of the reverse transcriptase for $5 \mathrm{~min}$ at $95^{\circ} \mathrm{C}, \mathrm{PCR}$ and the resulting relative increase in reporter fluorescent dye emission were monitored in real time using an Mx3000P QPCR system (Stratagene, La Jolla, CA, USA). In the SYBR Green assay, primer pairs were designed using the Primer Express software program (Applied Biosystems). The primers for each gene are listed in Table 3. Thermal-cycling conditions included initialsample incubation at $50^{\circ} \mathrm{C}$ for $2 \mathrm{~min}$ and at $95^{\circ} \mathrm{C}$ for 10 min, followed by 40 cycles at $95^{\circ} \mathrm{C}$ for $15 \mathrm{~s}$ and at $60^{\circ} \mathrm{C}$ for $1 \mathrm{~min}$. The relative differences in the initial amounts of each mRNA (or cDNA) species were determined by comparing the $\mathrm{C}_{\mathrm{T}}$ values. Standard curves for each gene were generated by serial dilution of the plasmid containing the corresponding cDNA to quantify the mRNA concentrations. We confirmed the melting curve for detecting the SYBR Green-based objective amplicon, because SYBR Green also detects any double-stranded DNA including primer dimers, contaminating DNA, and PCR products from misannealed primers. Contaminating DNA or primer dimers would show up as a peak separate from the desired amplicon peak. The expression ratio of each gene to GAPDH mRNA was calculated to adjust for variations in the RT-PCR reaction. All values are presented as means \pm SEM. QPCR was replicated as follows: for the Day 45 and Day 95 samples, QPCR data were collected in biological duplicate from $\mathrm{n}=3$ animals and technical duplicates $(\mathrm{n}=2)$ were performed on one animal sample (six data in total). For the Day 135 samples, QPCR data were collected in biological duplicate $(\mathrm{n}=2)$ and technical duplicate ( $\mathrm{n}$ $=2$ ) from one animal sample (four data in total). Statistical analysis was performed using one-way ANOVA followed by the Tukey-Kramer multiple-comparison test. Differences were considered significant at $P<0.05$.

\section{Production and purification of recombinant proteins}

The oPRP2 sequences encoding the mature-protein region, which combined the FLAG and $6 \times$ His epitope tag sequences, were inserted into a pFLAG-CMV-3 vector (Sigma). The constructed plasmid was transfected into HEK 293 cells using FuGENE 6 (Roche Diagnostics, Basel, Switzerland) for transient transfection. Stably transfected HEK 293 cells were adapted to suspension culture in a spinner flask using 293 SFM II medium (Invitrogen, Gibco) and cultured in an atmosphere of $5 \% \mathrm{CO}_{2}$ in air at $37^{\circ} \mathrm{C}$ for 3 days. The medium was separated by centrifugation.

Recombinant FLAG-tag and $6 \times$ His-tag fusion proteins were purified using the $6 \times$ His-tag portion. Approximately 1 liter of conditioned medium was processed at a time. Medium to which $1 \mathrm{ml} \mathrm{Ni}$ Sepharose 6 Fast Flow (Amersham Bioscience, Buckinghamshire, UK) was added was mixed and equilibrated with $20 \mathrm{mM}$ sodium phosphate buffer, $\mathrm{pH} 8.0$, containing $300 \mathrm{mM} \mathrm{NaCl}$ and 20 $\mathrm{mM}$ imidazole. Only the $6 \times$ His-tag proteins bind to the Ni Sepharose 6 Fast Flow carrier. The medium with carrier was chromatographed on a PD-10 column (Amersham Bioscience). The fractions with carrier were washed with $20 \mathrm{mM}$ imidazole. The fractions were eluted with $250 \mathrm{mM}$ imidazole.

\section{Western blot analysis}

One ng of purified protein was loaded on each lane, separated by SDS-PAGE, and electrophoretically transferred on to a polyvinylidene-difluoride membrane [58]. West-

Table 3: Oligonucleotide primers used for QPCR analysis

\begin{tabular}{cccc}
\hline Gene & Primer & Sequence & Position \\
\hline oPRPI & Forward & 5' ATATGCCCAGGGCAAACTGT 3' & $294-313$ \\
$($ AB231297 $)$ & Reverse & 5' AATCGAAGGCATTGGTTTGG 3' & $358-339$ \\
oPRP2 & Forward & $5^{\prime}$ TGGAAGATGTACGAGGCTCGT 3' & $590-610$ \\
$($ AB231298 $)$ & Reverse & 5' CGCCTATCTTCATCGCTGGA 3' & $631-612$ \\
oGAPDH & Forward & 5' GCCATCACCATCTTCCAGGA 3' & $81-100$ \\
$($ AF030943 $)$ & Reverse & 5' CCACGTACTCAGCACCAGCA 3' & $150-131$
\end{tabular}


ern blotting was performed using the method of Towbin et al. [59]. Briefly, the membrane was blocked in $10 \%$ skimmed milk overnight and incubated with mouse antiFLAG M2 (Sigma) for $1 \mathrm{~h}$ at room temperature, followed by incubation with anti-mouse IgG conjugated with alkaline phosphatase (Sigma) (diluted 1:3000) for $1 \mathrm{~h}$ at room temperature. Immunopositive bands were stained using NBT (Bio-Rad, Hercules, CA, USA) and BCIP (BioRad).

\section{Bioassay of lactogenic activity using Nb2 lymphoma cells} Lactogenic activity was assessed by the rat Nb2 lymphoma cell proliferation assay $[60,61]$. Nb2 lymphoma cells were routinely grown in Dulbecco's modified Eagle's Medium (DMEM) and Ham's F12 combined medium (1:1) (Sigma) supplemented with $50 \mu \mathrm{M}$ 2-mercaptoethanol, $100 \mathrm{U} / \mathrm{ml}$ penicillin and $100 \mu \mathrm{g} / \mathrm{ml}$ streptomycin, and containing both 10\% HS and 10\% FBS (maintenance medium: $\mathrm{MM}$ ), in an atmosphere of $5 \% \mathrm{CO}_{2} / 95 \%$ air at $37^{\circ} \mathrm{C}$. Twenty-four hours before initiation of the assay the cells were harvested, washed with supplemented Fischer's medium containing only $10 \%$ HS (stationary medium: $\mathrm{SM}$ ) and diluted to $1 \times 10^{6}$ cells $/ \mathrm{ml}$. At the initiation of the assay, cells were washed and aliquotted into $16-\mathrm{mm}$ wells $\left(1 \times 10^{6} \mathrm{cells} / \mathrm{ml} /\right.$ well $)$ of a 24 -well culture plate. Ovine prolactin (oPRL: positive control), bPL (positive control), bPRP1 and oPRP2 preparations were added at various concentrations and the cells were incubated for an additional $72 \mathrm{~h}$. Samples of treated cells were collected and counted in a Sysmex Microcell counter (Model CC-110; TOA Medical Electronics, Tokyo, Japan). Treatments were performed in quadruplicate.

\section{Authors' contributions}

KU participated in the design of the study, carried out the mRNA cloning, QPCR and in situ hybridization studies, and wrote the manuscript. TT participated in the design and coordination of the study and performed the recombinant protein production, Western blotting and Nb2 bioassay. KU, TT and MH collected the sheep tissue samples. $\mathrm{KO}$ and $\mathrm{MH}$ carried out the preparations for natural mating and all animal care. $\mathrm{KH}$ participated in the design and coordination of the study and helped to draft the manuscript. All authors read and approved the final manuscript.

\section{Acknowledgements}

This research was supported by a grant from the Research Project for Utilizing Advanced Technologies (05-1770) from the Ministry of Agriculture, Forestry and Fisheries of Japan; grants (Kiban-kenkyu C 17580284; Kibankenkyu B 17380 172) from the Ministry of Education, Culture, Sport, Science and Technology of Japan; and a grant from the Animal Remodeling Project (05-20I) at the National Institute of Agrobiological Sciences. We appreciate a review of the manuscript prior to submission by BioMedES (Aberdeen, UK).

\section{References}

I. Ushizawa K, Hashizume K: Biology of the PRL family in bovine placenta. II. Bovine prolactin-related proteins: their expression, structure and proposed roles. Anim Sci J 2006, 77: 18-27.

2. Soares MJ: The prolactin and growth hormone families: pregnancy-specific hormones/cytokines at the maternal-fetal interface. Reprod Biol Endocrinol 2004, 2:5I.

3. Larson JH, Kumar CG, Everts RE, Green CA, Everts-van der Wind A, Band MR, Lewin HA: Discovery of eight novel divergent homologs expressed in cattle placenta. Physiol Genomics 2006, 25:405-4I3.

4. Sakal E, Bignon C, Chapnik-Cohen N, Daniel N, Paly J, Belair L, Djiane J, Gertler A: Cloning, preparation and characterization of biologically active recombinant caprine placental lactogen. J Endocrinol 1998, 159:509-518.

5. Ushizawa K, Takahashi T, Hosoe M, Kizaki K, Abe Y, Sasada H, Sato E, Hashizume K: Gene expression profiles of novel caprine placental prolactin-related proteins similar to bovine placental prolactin-related proteins. BMC Dev Biol 2007, 7:16.

6. Colosi P, Thordarson G, Hellmiss R, Singh K, Forsyth IA, Gluckman $P$, Wood WI: Cloning and expression of ovine placental lactogen. Mol Endocrinol 1989, 3: I 462-1469.

7. Schuler LA, Shimomura K, Kessler MA, Zieler CG, Bremel RD: Bovine placental lactogen: molecular cloning and protein structure. Biochemistry 1988, 27:8443-8448.

8. Xie S, Green J, Roberts RM: Expression of multiple genes for pregnancy-associated glycoproteins in the sheep placenta. Adv Exp Med Biol 1998, 436:195-200.

9. Green JA, Xie S, Quan X, Bao B, Gan X, Mathialagan N, Beckers JF, Roberts RM: Pregnancy-associated bovine and ovine glycoproteins exhibit spatially and temporally distinct expression patterns during pregnancy. Biol Reprod 2000, 62:1624-1631.

I0. Garbayo JM, Green JA, Manikkam M, Beckers JF, Kiesling DO, Ealy $A D$, Roberts RM: Caprine pregnancy-associated glycoproteins (PAG): their cloning, expression, and evolutionary relationship to other PAG. Mol Reprod Dev 2000, 57:3 II-322.

II. Garbayo JM, Serrano B, Lopez-Gatius F: Identification of novel pregnancy-associated glycoproteins (PAG) expressed by the peri-implantation conceptus of domestic ruminants. Anim Reprod Sci 2008, 103: 120-34.

12. Imakawa K, Anthony RV, Kazemi M, Marotti KR, Polites HG, Roberts RM: Interferon-like sequence of ovine trophoblast protein secreted by embryonic trophectoderm. Nature 1987, 330:377-379.

13. Farin CE, Imakawa K, Hansen TR, McDonnell J], Murphy CN, Farin PW, Roberts RM: Expression of trophoblastic interferon genes in sheep and cattle. Biol Reprod 1990, 43:210-218.

14. Baumbach GA, Duby RT, Godkin JD: N-glycosylated and unglycosylated forms of caprine trophoblast protein-I are secreted by preimplantation goat conceptuses. Biochem Biophys Res Commun 1990, I72:16-2I.

15. MacLean JA 2nd, Roberts RM, Green JA: Atypical Kunitz-type serine proteinase inhibitors produced by the ruminant placenta. Biol Reprod 2004, $71: 455-463$.

16. MacLean JA 2nd, Chakrabarty A, Xie S, Bixby JA, Roberts RM, Green JA: Family of Kunitz proteins from trophoblast: expression of the trophoblast Kunitz domain proteins (TKDP) in cattle and sheep. Mol Reprod Dev 2003, 65:30-40.

17. Xie SC, Low BG, Nagel RJ, Kramer KK, Anthony RV, Zoli AP, Beckers $J F$, Roberts RM: Identification of the major pregnancy-specific antigens of cattle and sheep as inactive members of the aspartic proteinase family. Proc Natl Acad Sci USA 1991, 88: $10247-1025 \mid$.

18. Spencer TE, Johnson GA, Bazer FW, Burghardt RC, Palmarini M: Pregnancy recognition and conceptus implantation in domestic ruminants: roles of progesterone, interferons and endogenous retroviruses. Reprod Fertil Dev 2007, 19:65-78.

19. Soares MJ, Alam SMK, Konno T, Ho-chen JK, Ain R: The prolactin family and pregnancy-dependent adaptations. Anim SciJ 2006, 77:1-9.

20. Ushizawa K, Kaneyama K, Takahashi T, Tokunaga T, Tsunoda $Y$, Hashizume $\mathrm{K}$ : Cloning and expression of a new member of prolactin-related protein in bovine placenta: bovine prolactin-related protein-VII. Biochem Biophys Res Commun 2005, 326:435-44I. 
21. Ushizawa K, Takahashi T, Hosoe M, Kaneyama K, Hashizume K: Cloning and expression of two new prolactin-related proteins, prolactin-related protein-VIII and -IX, in bovine placenta. Reprod Biol Endocrinol 2005, 3:68.

22. Byatt JC, Bremel RD: Lactogenic effect of bovine placental lactogen on pregnant rabbit but not pregnant heifer mammary gland explants. J Dairy Sci 1986, 69:2066-207I.

23. Anthony RV, Pratt SL, Liang R, Holland MD: Placental-fetal hormonal interactions: impact on fetal growth. J Anim Sci 1995, 73: $186|-| 87 \mid$.

24. Goffin V, Shiverick KT, Kelly PA, Martial JA: Sequence-function relationships within the expanding family of prolactin, growth hormone, placental lactogen, and related proteins in mammals. Endocr Rev 1996, I 7:385-410.

25. Alam SM, Ain R, Konno T, Ho-Chen JK, Soares MJ: The rat prolactin gene family locus: species-specific gene family expansion. Mamm Genome 2006, I 7:858-877.

26. Wiemers DO, Shao LJ, Ain R, Dai G, Soares MJ: The mouse prolactin gene family locus. Endocrinology 2003, I44:3। 3-325.

27. Takahashi T: Biology of the PRL family in bovine placenta. I. Bovine placental lactogen: expression, structure and proposed roles. Anim Sci J 2006, 77:10-17.

28. Al-Gubory KH, Camous S, Germain G, Bolifraud P, Nicole A, Ceballos-Picot I: Reconsideration of the proposed luteotropic and luteoprotective actions of ovine placental lactogen in sheep: in vivo and in vitro studies. I Endocrinol 2006, I 88:559-568.

29. Song G, Bazer FW, Wagner GF, Spencer TE: Stanniocalcin (STC) in the endometrial glands of the ovine uterus: regulation by progesterone and placental hormones. Biol Reprod 2006, 74:913-922.

30. Patel OV, Yamada O, Kizaki K, Todoroki J, Takahashi T, Imai K, Schuler LA, Hashizume K: Temporospatial expression of placental lactogen and prolactin-related protein-I genes in the bovine placenta and uterus during pregnancy. Mol Reprod Dev 2004, 69:146-152

31. Yamada O, Todoroki J, Kizaki K, Takahashi T, Imai K, Patel OV, Schuler LA, Hashizume K: Expression of prolactin-related protein $I$ at the fetomaternal interface during the implantation period in cows. Reproduction 2002, 1 24:427-437.

32. Sinha YN: Structural variants of prolactin: occurrence and physiological significance. Endocr Rev 1995, 16:354-369.

33. Kessler MA, Schuler LA: Structure of the bovine placental lactogen gene and alternative splicing of transcripts. DNA Cell Biol 1991, 10:93-104.

34. Hashizume K, Ushizawa K, Patel OV, Kizaki K, Imai K, Yamada O, Nakano H, Takahashi T: Gene expression and maintenance of pregnancy in bovine: roles of trophoblastic binucleate cellspecific molecules. Reprod Fertil Dev 2007, I9:79-90.

35. Mittra I: A novel "cleaved prolactin" in the rat pituitary: part I. Biosynthesis, characterization and regulatory control. Biochem Biophys Res Commun 1980, 95: I750-1759.

36. Sinha YN, Gilligan TA: A cleaved form of prolactin in the mouse pituitary gland: identification and comparison of in vitro synthesis and release in strains with high and low incidences of mammary tumors. Endocrinology 1984, I | 4:2046-2053.

37. Sinha YN, Gilligan TA, Lee DW, Hollingsworth D, Markoff E: Cleaved prolactin: evidence for its occurrence in human pituitary gland and plasma. I Clin Endocrinol Metab 1985 60:239-243.

38. Ferrara N, Clapp C, Weiner R: The $16 \mathbf{K}$ fragment of prolactin specifically inhibits basal or fibroblast growth factor stimulated growth of capillary endothelial cells. Endocrinology 1991, I 29:896-900.

39. Clapp C, Martial JA, Guzman RC, Rentier-Delure F, Weiner RI: The I 6-kilodalton $\mathbf{N}$-terminal fragment of human prolactin is a potent inhibitor of angiogenesis. Endocrinology 1993 , 133:1292-1299.

40. Clapp C, Weiner RI: A specific, high affinity, saturable binding site for the 16-kilodalton fragment of prolactin on capillary endothelial cells. Endocrinology 1992, 130:1380-1386.

4I. Jackson D, Volpert OV, Bouck N, Linzer DI: Stimulation and inhibition of angiogenesis by placental proliferin and proliferinrelated protein. Science 1994, 266:|58|-|584.

42. Volpert O, Jackson D, Bouck N, Linzer DI: The insulin-like growth factor II/mannose 6-phosphate receptor is required for proliferin-induced angiogenesis. Endocrinology 1996, I 37:387/-3876.
43. Toft DJ, Rosenberg SB, Bergers G, Volpert O, Linzer DI: Reactivation of proliferin gene expression is associated with increased angiogenesis in a cell culture model of fibrosarcoma tumor progression. Proc Natl Acad Sci USA 200I, 98: | 3055-13059.

44. Lin J, Linzer DI: Induction of megakaryocyte differentiation by a novel pregnancy-specific hormone. I Biol Chem 1999, 274:2 | 485-2| 489 .

45. Bhattacharyya S, Lin J, Linzer DI: Reactivation of a hematopoietic endocrine program of pregnancy contributes to recovery from thrombocytopenia. Mol Endocrinol 2002, I 6:1386-1393.

46. Zhou B, Lum HE, Lin J, Linzer DI: Two placental hormones are agonists in stimulating megakaryocyte growth and differentiation. Endocrinology 2002, I 43:428I-4286.

47. Ain R, Tash JS, Soares MJ: Prolactin-like protein-A is a functiona modulator of natural killer cells at the maternal-fetal interface. Mol Cell Endocrinol 2003, 204:65-74.

48. Muller H, Liu B, Croy BA, Head JR, Hunt JS, Dai G, Soares MJ: Uterine natural killer cells are targets for a trophoblast cell-specific cytokine, prolactin-like protein A. Endocrinology 1999, | 40:27| I-2720.

49. Ashkar AA, Croy BA: Functions of uterine natural killer cells are mediated by interferon gamma production during murine pregnancy. Semin Immunol 200 I, I 3:235-24 I

50. Ain R, Canham LN, Soares MJ: Gestation stage-dependent intrauterine trophoblast cell invasion in the rat and mouse: novel endocrine phenotype and regulation. Dev Biol 2003, 260: $176-190$.

5I. Nakano H, Takahashi T, Imai K, Hashizume K: Expression of placental lactogen and cytokeratin in bovine placental binucleate cells in culture. Cell Tissue Res 200I, 303:263-270.

52. Saitou N, Nei N: A neighbor-joining method: a new method for constructing phylogenetic tree. Mol Biol Evol 1987, 44:406-425.

53. Page RDM: TREEVIEW: An application to display phylogenetic trees on personal computers. Comput Appl Biosci 1996, I 2:357-358.

54. Ogata K, Umeyama $\mathrm{H}$ : An automatic homology modeling method consisting of database searches and simulated annealing. J Mol Graphics Mod 2000, 1 8:258-272.

55. Modeling Service for Protein [http://www.pharm.kitasatou.ac.jp/fams/index.html]

56. Bernstein $\mathrm{HJ}$ : Recent changes to RasMol, recombining the variants. Trends Biochem Sci 2000, 25:453-455.

57. RasMol 2.7.3 [http://www.bernstein-plus-sons.com/software/ras $\mathrm{mol} /]$

58. Laemmli UK: Cleavage of structural proteins during the assembly of the head of bacteriophage T4. Nature 1970 , 227:680-685

59. Towbin H, Staehelin T, Gordon J: Electrophoretic transfer of proteins from polyacrylamide gels to nitrocellulose sheets: procedure and some applications. Proc Natl Acad Sci USA 1979, 76:4350-4354.

60. Tanaka T, Shiu RP, Gout PW, Beer CT, Noble RL, Friesen HG: A new sensitive and specific bioassay for lactogenic hormones: measurement of prolactin and growth hormone in human serum. I Clin Endocrinol Metab 1980, 5 I:1058-1063.

61. Schellenberg C, Friesen HG: The bioassay of bovine placental lactogen. Endocrinology 1982, I I I:2 I 25-2 I 28.

Publish with Bio Med Central and every scientist can read your work free of charge

"BioMed Central will be the most significant development for disseminating the results of biomedical research in our lifetime. "

Sir Paul Nurse, Cancer Research UK

Your research papers will be:

- available free of charge to the entire biomedical community

- peer reviewed and published immediately upon acceptance

- cited in PubMed and archived on PubMed Central

- yours - you keep the copyright
BioMedcentral 